\title{
Increasing Student Access to High-Impact Practices: Signature Learning Experiences at Elizabethtown College
}

\author{
E. Fletcher McClellan \\ Elizabethtown College, USA
}

\begin{abstract}
High-impact practices (HIPs) positively impact student learning in underserved populations, yet such groups are less likely to participate in these engaging activities. This paper describes an "embedded" approach in which all students at Elizabethtown College, a small, private institution in Pennsylvania, must choose and successfully complete two of five designated upper-year HIPs or Signature Learning Experiences (SLEs) in the curriculum and cocurriculum. Special attention is given to how expanding access to HIPs became a strategic priority, the process by which the SLE/HIP requirement was adopted, and the early steps institutional leaders took to promote effective implementation of the requirement.
\end{abstract}

\section{Introduction}

Like many small, private colleges in the U.S., Elizabethtown College in Lancaster County, Pennsylvania is tuition-driven, has a relatively small endowment, competes with other small colleges with stronger reputations and deeper pockets for a small demographic pool of students and families who have been ravaged by the Great Recession, and faces increased scrutiny from students, families, accreditors and other stakeholders about the cost and value of higher education.

In this competitive marketplace, Elizabethtown has fared well. We have a beautiful campus, balance our budgets, and keep our comprehensive fee lower than the highest-priced national liberal arts institutions. We remain selective, recruit sufficient qualified students to meet our budget targets (enrollment of 1,800 full-time students of traditional age, co-educational, over $80 \%$ residential), and have higher first-year to sophomore retention and graduation rates than comparable colleges. We offer a variety of professional and liberal arts programs, invest in full-time faculty with impressive records as teacher-scholars, specialize in developing highachieving students (35\% of whom are first-generation college), and have enviable job placement rates.

At the same time, our admissions director reports that, in addition to the usual competition from state colleges and universities, a significant number of families with ability to pay are turning us down in favor of lesser-quality, lower-cost, private colleges. We are running harder to stay in the same place.

To address these challenges, our new president successfully led the development and approval of a five-year (2012-17) strategic plan in his first year of office. This plan is ambitious, calling for Elizabethtown to change its Carnegie status from BAbalanced to national liberal arts. One major area of emphasis is reform of the educational program through what the plan calls "Real World Learning." Following the lead of the Association of American Colleges \& Universities (AAC\&U) and the National Survey of Student Engagement (NSSE), the strategic plan focused on increasing student learning through engagement in High-Impact Practices (HIPs) [1], [2].

In 2012-13 the Elizabethtown faculty approved a new graduation requirement by which all students must successfully complete two of five HIPs (what the College calls Signature Learning Experiences or SLEs) beyond the first year: (1) internships, field experiences or practicums; (2) faculty-supervised research; (3) community-based learning; (4) crosscultural experiences, including study abroad; and (5) a capstone course, project or experience or a developmental portfolio. This past year, 2013-14, lists of approved courses and experiences for each SLE/HIP and a process for administering and 
assessing the impact of the requirement were approved. Current sophomores (the class of 2017) are the first cohort to come under the SLE/HIP mandate.

This paper describes the process by which the SLE/HIP requirement at Elizabethtown was developed and approved. For the most part, SLE/HIPs were embedded in the curriculum and co-curriculum, such that the elements for implementation of the program were already in place. Additionally, the paper discusses the need for thoughtful consideration of how to implement a SLE/HIP requirement which features student choice. The early implementation process at Elizabethtown will be featured with the recognition that much important work remains before the program can be declared a success.

\section{Development of the SLE/HIP requirement}

With the inauguration of Dr. Carl Strikwerda as the $14^{\text {th }}$ president of Elizabethtown College in fall 2011, the College launched a process to develop a five-year strategic plan. To address the goal of developing an educational program aimed at Real World Learning, a working group on learning modes and outcomes was created. Chaired by the Dean of Faculty and Dean of Students, the committee examined how students learn best. Early on, we focused on the work of George Kuh on high-impact practices, i.e. deeply engaging educational activities (first-year seminars, common intellectual experiences, living-learning communities, writing-intensive courses, collaborative assignments and projects, study abroad and other programs that explore different cultures and worldviews, service-learning, supervised research, internships, and capstone courses and projects) that promote deeper learning as defined in NSSE student surveys [1], [2], [3] and more direct measures. [4,5] AAC\&U has championed this approach as a means to enhance educational opportunities for underserved populations such as first-generation students and racial and ethnic minorities. [6]

High-impact practices have been featured in Elizabethtown's curriculum for over two decades. All students take an academically-focused first-year seminar and a writing-intensive course in the general education program, and many participate in livinglearning communities. According to a NSSE survey of the campus administered in spring 2014, first-year students at Elizabethtown are more likely to engage in high-impact activities, including courses with service- learning, than are students at regional small colleges or more selective liberal arts schools in our market.

As for HIPs in the later stages of the college career, a transcript analysis conducted by the institutional research office in 2013 showed $80-85 \%$ of Elizabethtown graduates completed at least two of the five upper-level HIPs that were eventually designated in the SLE requirement. This was comparable to the number of HIP experiences by seniors at regional peer institutions, according to NSSE, though there were some differences. For example, Elizabethtown students were more likely to participate in communitybased learning (70\% of all students) internships and field experiences $(60 \%)$ and less likely to study abroad (25\%).

Similar to the findings of national studies, our analysis of the 15-20\% of students who did not complete at least two upper-level HIPs showed a higher proportion of first-generation students and other traditionally underserved groups than that found in the general student body [2], [3], [6]. Engagement data from the 2011 Elizabethtown NSSE, repeated in the 2014 survey, showed above-average levels of collaborative learning and student-faculty interaction for both first-year students and seniors. However, our first-years and seniors reported fewer discussions with diverse others than did students at comparable colleges. Moreover, the level of academic challenge for seniors, particularly in higher-order, integrative, and reflective learning activities, was below that of peer institutions.

Noting the drop-off in academic challenge between the first year and the senior year, as well as wanting to provide our first-generation and diverse populations a richer educational experience, the strategic planning working group recommended in December 2011 that the College should increase opportunities for undergraduate research, identify high-quality internships and field placements, and provide more common intellectual experiences and contexts for cross-cultural engagement.

The recommendations of the Learning Modes and Outcomes committee were integrated in the College's Strategic Plan, which was approved by the faculty and the Board of Trustees in April 2012. Goal Two of the plan aimed to "Foster a campus culture that provides all students with pathways and opportunities for Real World Learning." To reach this goal, several strategies were specified, among which was to design "intentional pathways and advising for all students that integrate curricular and co-curricular learning, provide 'high impact practices' such as 
undergraduate research, internships, study abroad, and civic engagement, and encourage student assessment of individual learning and progress toward institutional learning goals."

Beginning in summer 2012, efforts were devoted to translating the Real World Learning concept into concrete proposals and securing faculty support. Five "action teams," each focused on a particular impactful practice such as undergraduate research, developed specific proposals. In early 2013 the faculty curriculum committee recommended what became the SLE requirement. Though the proposal was approved with few changes by the faculty later that spring, it was not without controversy. Opponents questioned the capacity of the college to provide all students with at least two SLEs, whether all students were capable of successfully completing SLEs, how much value in learning the SLE requirement would add, and the routinization of what were previously considered special learning opportunities. Proponents countered that because of our success in promoting high-impact practices over the past decade, Elizabethtown was in a position to offer guarantees to all students without a major infusion of resources. High-impact experiences were connected to positive outcomes for students (deeper learning, marketable skills, jobs, graduate schools) and for the College (student satisfaction, job and graduate school placement). In addition, Elizabethtown would associate itself with national liberal arts institutions which emphasize HIPs and gain strategic advantages over peer colleges. After a month of contentious debate, the faculty assembly approved the SLE requirement by a $60 \%-40 \%$ margin on April $30,2013$.

\section{Early implementation of the SLE/HIP requirement}

Implementation of the SLE/HIP requirement posed several challenges for academic leadership. First, the structure and culture of academic advising had to change, so that the question of how students will meet the requirement can become an opportunity for meaningful conversations between students and faculty advisors and not a mechanical exercise in prescriptive advising. Second, additional resources were needed to support time and labor-intensive HIPs such as supervising student research. This required innovative ways of thinking about faculty workload, staffing, and compensation. Third, there needed to be a thoughtful and inclusive faculty development program in teaching and advising HIPs that could elicit the participation of recalcitrant faculty and departments, especially among those who relied on traditional modes of instruction or who saw student engagement as a distraction from "true" learning that comes from many hours of quiet study. [7] Finally, the impact of SLEs on student learning should be assessed in a variety of authentic and traditional ways. This required the development of measures of success for students and academic programs. Somehow SLE assessment data must be plugged into faculty and staff channels that will lead to continuous improvement of the educational program.

The last eighteen months have been devoted to addressing many of these implementation questions. Most of 2013-14 was consumed by efforts to develop definitions of the SLEs and a process for approving qualified courses and experiences. The main objective was to establish robust requirements for supervised research (advanced level aimed at creating or cocreating knowledge under faculty supervision), crosscultural experiences (living and studying at least 15 days in a different culture to promote meaningful engagement), and community-based learning (at least 15 days service learning connected to coursework). Capstone experiences were expanded to include developmental portfolios in such areas as education and engineering, in which students work with faculty through the college career to craft narratives and select artifacts that demonstrate satisfactory performance in core competencies.

In addition, following Kuh's recent call for expanding the notion of HIPs to include powerful outof-the-classroom opportunities [2], our definition process incorporated non-credit opportunities such as summer internships and co-curricular experiences, including a leadership development program run out of the Religious Life office.

As the process of approving definitions and lists of courses neared its conclusion, the end game resembled the sausage-making of legislation. Departments scrambled to add SLEs to their majors, trying to get at least two embedded in each program. The conundrum was that this contradicted the goal of student choice and defied logic. Departments may assume students will gravitate toward programs with many SLEs, but it is also possible that students will avoid them.

Also, individual faculty wanted SLE approval of their respective courses or experiences, but not all proposals satisfied the required definitions. In some cases an accommodation was made, e.g. permitting off-campus study tours during the regular academic 
year for less than 15 days to count as an SLE if the travel experience was integrated with course material.

Ultimately, a wide range of engaging educational opportunities, the vast majority of which were already embedded in the academic program, was approved. Capstone experiences included senior music recitals and art exhibits as well as major research projects. Contained in the internship category are student teaching and clinical practice activities in social work, occupational therapy and music therapy. Communitybased learning could involve not only traditional service projects but also applied research for client businesses and non-profit organizations.

Implementation has proceeded on several other fronts. The distinctiveness of Elizabethtown's SLE/HIP program is based on the idea that students choose the experiences that will help them reach their academic, career and personal goals. This means that the College's faculty-centered advising program must be second to none in its responsiveness to students. Prior to the spring 2014 advising period, when firstyear students are allowed to declare majors, all faculty received training on the SLE requirement, how it will be implemented, and how to work developmentally with students. The academic affairs and student life offices initiated a pilot sophomore year experience program in fall 2014 that we hope will provide a context for students to plan their SLEs thoughtfully as they construct pathways to success both during and after the college career.

In addition, we are increasing our supply of quality high-impact opportunities to meet the demand. Our summer research program, limited previously to the bench sciences, expanded to include all disciplines. The Dean of Faculty office funded several think-tanks, in which teams of students research questions of public concern and disseminate their findings. Academic departments such as Business and Engineering are forming community and business partnerships to provide new internship and co-op opportunities.

High-impact practices are successful in promoting deeper learning only if they are done well, i.e. high academic expectations are set, students spend sufficient time on task, there is meaningful faculty and peer interaction, timely and constructive feedback is provided, and so on. $[2,3,4,8]$ So, we are working to enhance the quality and rigor of our SLEs. For example, our Center for Excellence in Teaching and Learning will offer training to faculty who want to include service-learning in their courses. Furthermore, we are examining our compensation structure for faculty who engage in time-intensive supervision of SLEs and hope to provide further incentives to faculty who organize short-term study abroad programs.

How will we know whether the SLE/HIP program is succeeding? The College administers NSSE at regular intervals and has baseline data for comparing student learning and satisfaction for graduating classes before and after the requirement was established. The College surveys students one year and five years after graduation, so we can measure the success of classes pre- and post-SLE. Since NSSE surveys both first-year and senior students, we can examine how much value SLE/HIPs add over the course of the college career and which SLE/HIPs add the most value. For the cross-cultural experience and community-based learning SLEs, we will use AAC\&U VALUE rubrics in cross-cultural learning and civic engagement [9] to measure depth of learning. We can also see whether the guarantee will produce greater learning, satisfaction and success among first-generation and other educationally disadvantaged groups, compared to that of the student body as a whole, as national studies show [2], [3], [6].

\section{Conclusions}

The past three years of developing the SLE/HIP requirement have resulted in what we believe is a distinctive model for increasing access to high-impact practices. The distinguishing features include, first of all, a guarantee that all students will engage in at least two upper-level HIPs. Second, our approach focuses on student choice, rather than specifying particular SLE/HIPs that may or may not be appropriate to student goals or prospects for success. Third, powerful co-curricular experiences that reflect best practices of teaching and learning [8] are included among the SLE/HIPs which students can choose. Fourth, each experience must satisfy robust definitions of HIPs designed to produce deeper learning. Fifth and finally, the vast majority of experiences on the master list of qualified SLE/HIPs are already embedded in the curriculum and co-curriculum, such that implementing the requirement did not require a massive infusion of resources.

The process for developing the SLE/HIP program also deserves attention. Contrary to our bold claims and hopes for the program itself, we admit candidly that other pathways to formulating and securing support for curriculum change may have produced a different, though not necessarily better, result. It could be argued that a top-down model was 
followed, fueled by a new president and a strategic planning process that was completed within an academic year.

On the other hand, faculty involvement was more pronounced in the second year, as the SLE/HIP proposal was derived from the goals and objectives of the strategic plan. Brainstorming by faculty action teams took place in the summer and fall, leading to faculty governance action on a concrete proposal in 2012-13. The process of assembling the list of qualified SLE/HIP experiences in 2013-14 involved academic departments directly.

Though the proposal was adopted in spring 2013 and implementation was begun the next fall, it is possible that more time and faculty input for gestation could have produced greater faculty support at the time of passage. The perception that the SLE/HIP requirement was an "administration proposal" has hampered faculty enthusiasm for the guarantee. Students and parents are interested, though, and the admissions office has commented favorably that faculty and staff members are speaking the same language of the benefits of high-impact practices.

Positive features of the adoption process included a focus on student learning, use of the research on HIPs as a framework for discussion, and collaboration between the academic and student life deans. Another aspect was the important role of institutional research in determining how close the College was to achieving a universal HIP requirement, classifying SLE/HIP experiences that are not offered as traditional courses, and conducting surveys that will assist in assessment efforts.

Managing implementation of the requirement has proved to be a complex challenge. For the most part, the Dean of Faculty office has coordinated implementation efforts, which include working with faculty governance committees and academic departments to construct definitions and lists of qualified SLE/HIPs, examine how to compensate faculty properly for SLE/HIP supervision, and assess the institutional and learning impact of the program. Consultation with the faculty development committee and the teaching and learning center was needed to provide training to faculty to advise for the requirement and effectively teach or supervise specific HIPs. Another important administrative task is securing sufficient resources from the operating budget and, if possible, external sources to maintain high-quality delivery of SLEs and promote new initiatives such as the sophomore year experience. Sometimes the dean works with the admissions and marketing offices to promote the program, reaching outside his area of expertise. The lesson for colleges interested in pursuing a HIP requirement is to think carefully about what kinds of structure, process and leadership are needed to implement the program effectively.

To be sure, the SLE/HIP program will no doubt be modified as we learn from the experiences of the initial graduating classes. Currently the requirement can be fulfilled with two experiences in the same SLE, e.g. two internships. An argument can be made that a student's educational experience will be enhanced if he/she participates in two different SLE activities. Humanities faculty members have observed that professional programs have natural advantage in the SLE competition, since internships and field experiences are embedded in their programs. Subsequently, it has been proposed that the SLE/HIP requirement should be modified to one SLE only in the major. Students would then need to look in general education, electives, a double major, a minor or the co-curriculum to obtain the second SLE.

Adopting an upper-level SLE/HIP requirement for all students has implications for curriculum and instruction generally. We plan to examine general education and major programs to see how well they prepare students to demonstrate competence in the knowledge, skills and dispositions necessary for success in SLEs. In particular, there is concern about our students' ethical awareness and capacity for moral and ethical reasoning and decision-making in a world with countless unstructured challenges.

Finally, since the impetus for reforming the educational program was to earn Elizabethtown national recognition, how can distinctive features of Real World Learning be developed and marketed? Already our marketing and communications office is featuring stories of students who have completed unique high-impact experiences. Traditional recruitment and retention measures, along with the results of our outcomes assessment program, described above, can provide evidence of the success of our approach.

Beyond that, the challenge for the College is whether it can customize the requirement to make it a truly individualized, "signature" experience, as well as ritualize it as a collective achievement for each graduating class. If we can accomplish that, the most enthusiastic promoters of the SLE/HIP program will be the students themselves. 


\section{References}

[1] Kuh, G. High-Impact Educational Practices: What They Are, Who Has Access to Them and Why They Matter, Association of American Colleges and Universities, Washington, DC, 2008.

[2] Kuh, G. and K. O’Donnell, Ensuring Quality and Taking High-Impact Practices to Scale, Association of American Colleges and Universities, Washington, DC, 2013.

[3] Brownell, J.E. and L.E. Swaner. Five High-Impact Practices, Association of American Colleges and Universities, Washington, DC, 2010.

[4] McCormick, A.C., R.C. Gonyea, and J. Kinzie, "Refreshing Engagement: NSSE at 13," Change: The Magazine of Higher Learning, Taylor \& Francis, Philadelphia, May/June 2013, 6-15.

[5] Pascarella, E.T. and C. Blaich, "Lessons from the Wabash National Study of Liberal Arts Education," Change: The Magazine of Higher Learning, Taylor \& Francis, Philadelphia, March/April 2013, 6-15.

[6] Finley, A. and T. McNair, Assessing Underserved Students' Engagement in High-Impact Practices, Association of American Colleges and Universities, Washington, DC, 2013.

[7] Arum, R. and J. Roska, Academically Adrift: Limited Learning on College Campuses, University of Chicago Press, Chicago, 2010.

[8] Chickering, A.W. and Z.F. Gamson, "Seven Principles for Good Practice in Undergraduate Education," AAHE Bulletin, American Association for Higher Education, Washington, DC, March 1987, 3-7.

[9] Rhodes, T., ed., Assessing Outcomes and Improving Achievement: Tips and Tools for Using Rubrics, Association of American Colleges and Universities, Washington, DC, 2010. 